\title{
MORPHOLOGY OF CAUDATE LOBE OF LIVER
}

\author{
Romi Sadanandan', Susan Varghese ${ }^{2}$ \\ 1 Professor and HOD, Department of Anatomy, Government TD Medical College, Alappuzha, Kerala. \\ ${ }^{2}$ Associate Professor, Department of Anatomy, Government TD Medical College, Alappuzha, Kerala.
}

\section{ABSTRACT}

\section{BACKGROUND}

Caudate lobe morphology has significance in diagnostic imaging and in minimally invasive surgery. The present study aims to assess the morphology of caudate lobe and its anatomical independence from rest of the liver, as it may be differentially affected in liver pathologies and may be beneficial for radiologists and surgeons.

\section{MATERIALS AND METHODS}

Parameters like vertical and transverse diameters of caudate lobe and right lobe were measured with vernier callipers and surface area calculated using butter paper. Biliary drainage, venous supply and arterial supply of 36 adult human cadaveric livers were noted by gross dissection.

\section{RESULTS}

Papillary processes, caudate processes and notches were found in majority of caudate lobes studied. Caudate lobes varied in their shapes and measurements. An accessory fissure and lobe were seen. Ratio of surface area of caudate lobe to right lobe varied from 0.061 to 0.410 . Portal vein and hepatic artery supplied the caudate lobes by their left branches and biliary drainage was also through left hepatic duct in majority of caudate lobes.

\section{CONCLUSION}

The anatomical independence of caudate lobe was assessed and confirmed by its mode of blood supply and biliary drainage. All the caudate lobes had independent vessels and ducts. The papillary process of caudate lobe can cause pitfalls in interpretation of $\mathrm{C} T$ images at the porta hepatis. Caudate lobe variations are important for surgeons and radiologists alike for avoiding misinterpretation and for better surgical outcome.

\section{KEYWORDS}

Caudate Lobe, Liver, Biliary Drainage, Portal Vein, Hepatic Artery.

HOW TO CITE THIS ARTICLE: Sadanandan R, Varghese S. Morphology of caudate lobe of liver. J. Evolution Med. Dent. Sci. 2017;6(90):6268-6272, DOI: 10.14260/jemds/2017/1363

\section{BACKGROUND}

The liver has been divided into right, left, caudate and quadrate lobes by the peritoneal reflections and by the attachment of ligaments. Caudate lobe is so named, not because it is caudal in position, but because it often gives rise to a tail in the form of an elongated papillary process. The caudate lobe, also called spigelian lobe seems to be different from the rest of the liver in that it behaves in a paradoxical manner, particularly in cases of cirrhosis. It is anatomically independent from rest of the liver.

It is bounded on the left by fissure for ligamentum venosum, inferiorly by porta hepatis, and on the right by inferior vena cava. It is continuous superiorly with the superior surface. It is subdivided into caudate lobe proper, and the papillary process, the caudate process and the paracaval portion which is anterior to inferior vena cava. The caudate lobe is connected to the right lobe of liver by the caudate process which passes laterally between portal vein and inferior vena cava at the porta hepatis. Sometimes, the

'Financial or Other Competing Interest': None.

Submission 09-10-2017, Peer Review 03-11-2017,

Acceptance 09-11-2017, Published 20-11-2017.

Corresponding Author:

Dr. Susan Varghese,

Puthenveedu, T. C. 4/1060,

P. C. Lane, Kowdiar,

Trivandrum-695003.

E-mail: susu_dony@yahoo.com

DOI: $10.14260 /$ jemds $/ 2017 / 1363$
Caudate process may be elevated in appearance. Papillary process passes to the left and anteriorly to the region of superior recess of omental bursa. There may be grooves or fissures separating the caudate and papillary process from rest of the liver. Its complex anatomy may cause difficulty in interpretation of cross sectional images, particularly if papillary process is involved in diseases or if it is enlarged.

Liver can be divided into lobes based on the bifurcation of portal vein into left and right branches. According to Couinaud, portal vein divides into left and right branches both of which divide again thus producing four main branches, each supplying a portal sector. Each portal sector is divided again by portal vein. The eight segments are numbered I to VIII clockwise from inferior vena cava. Caudate lobe is the segment I in Couinaud's classification and it is the only segment which receives blood independently from both left and right branches of portal vein. Portal vein divides into right and left branches at the hilum. Left portal branch has a longer extraparenchymal course and tends to be slightly more horizontal than the right branch. It has horizontal and vertical portions. Horizontal portion runs along the base of segment VI and often gives branches to segment I and also to segment VI.

The Glissonian sheaths to segment I arises from both right and left main sheaths. The segment therefore receives vessels independently from left and right portal vein and hepatic arteries and drain independently into inferior vena cava by multiple small branches. Bile ducts draining segment 
I are closely related to the confluence of the right and left hepatic ducts.

Arterial blood from Hepatic artery accounts for only 20$25 \%$ of blood received by liver, is distributed initially to nonparenchymatous structures, particularly the intrahepatic bile ducts. Proper hepatic artery divides into right and left branches at the porta hepatis before they run into the parenchyma of the liver. Segmental arteries are usually end arteries and collaterals can occur between segments.

Shape of caudate lobe is variable as also its anterior and upper margin. Morphology of caudate lobe has significance in diagnostic imaging and also minimally invasive surgical approaches. The caudate lobe shows compensatory hypertrophy in cirrhosis and is spared from atrophy. Thus, we have taken up this study as it may give better surgical outcome.

\section{MATERIALS AND METHODS}

This study was done in 36 formalin fixed adult human livers obtained from the Department of Anatomy, Government T D Medical College, Alappuzha, Kerala.

\section{Study Design}

Descriptive study.

Diseased livers were excluded from the study. The gross anatomy of caudate lobe was studied for its shape, presence or absence of fissures, or notch and presence or absence of papillary and caudate processes and their variations. Caudate lobe area to right lobe area ratio (CL $\backslash R L)$ was also noted. The maximum transverse dimension of the caudate lobe and right lobe and the vertical extent of both caudate lobe and right lobe were measured using vernier callipers and measuring tape. The area of caudate lobes and right lobes were calculated by marking their outline on butter paper.

- $\quad$ Length of caudate lobe and right lobes were measured at the level of the maximum longitudinal extension.

- Transverse diameter of caudate lobe is the distance from the most medial margin to right lateral wall of the portal vein.

- Transverse diameter of right lobe extends from the right lateral wall of the portal vein to the most lateral margin of the right lobe.

The vessels and bile duct at porta hepatis were dissected and traced to the caudate lobe to see its supply and biliary drainage. All findings were documented.

The range of various parameters, mean and standard deviation were calculated manually.

\section{RESULTS AND ANALYSIS \\ Morphology of Caudate Lobe}

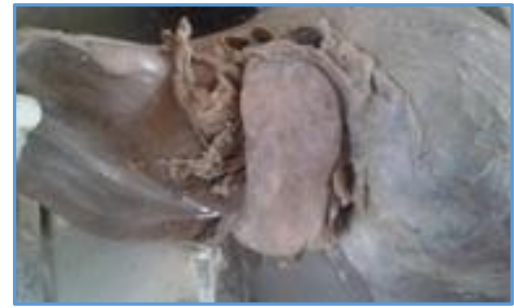

Figure I. Rectangular

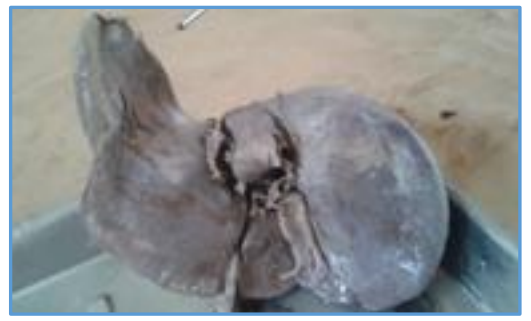

Figure II. Dumbbell shaped

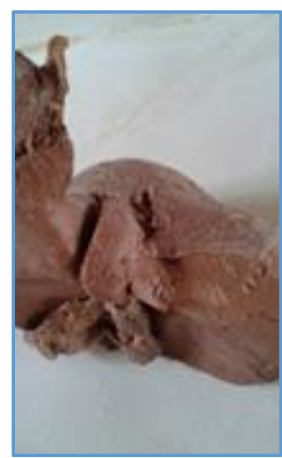

Figure III. Triangular

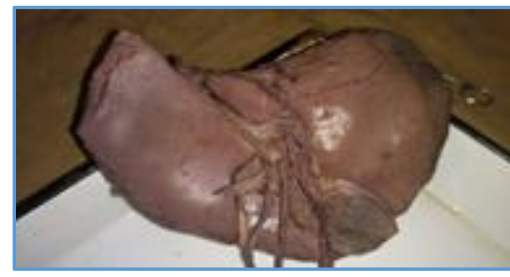

Figure IV. Elongated/Columnar

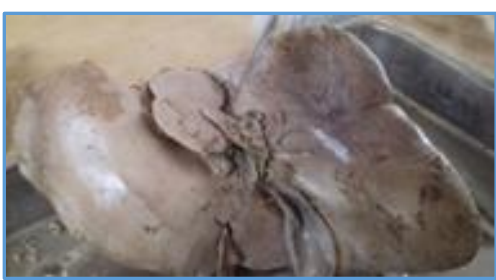

Figure V. Accessory Lobe

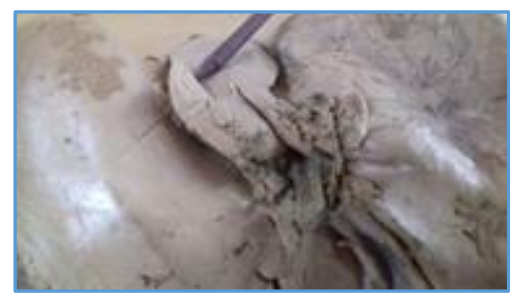

Figure VI. Accessory Fissure

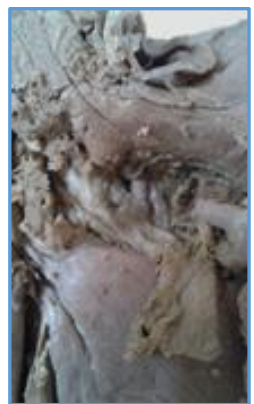

Figure VII. 2 Branches from Left PV 


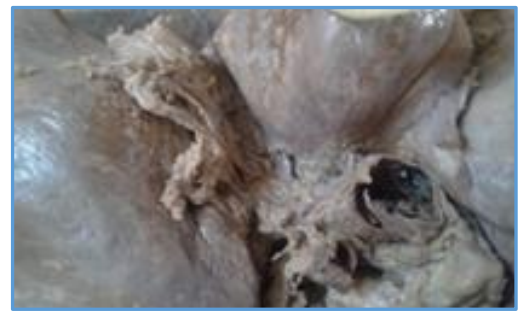

Figure VIII. Branches from Left and Right PV

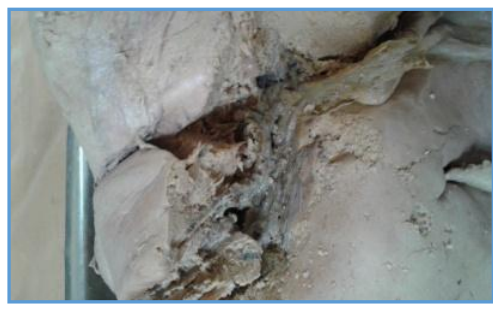

Figure IX. BR of Left H D

\begin{tabular}{|c|c|c|c|}
\hline $\begin{array}{c}\text { Sl. } \\
\text { No. }\end{array}$ & Shape of CL & $\begin{array}{c}\text { Number of } \\
\text { Cadaveric Livers }\end{array}$ & Percentage \\
\hline 1 & Rectangular & 22 & 61.11 \\
\hline 2 & Triangular & 6 & 16.67 \\
\hline 3 & Columnar/elongated & 6 & 16.667 \\
\hline 4 & Dumbbell shaped & 2 & 5.55 \\
\hline \multicolumn{4}{|c|}{ Table I. Shape of Caudate Lobes } \\
\hline
\end{tabular}

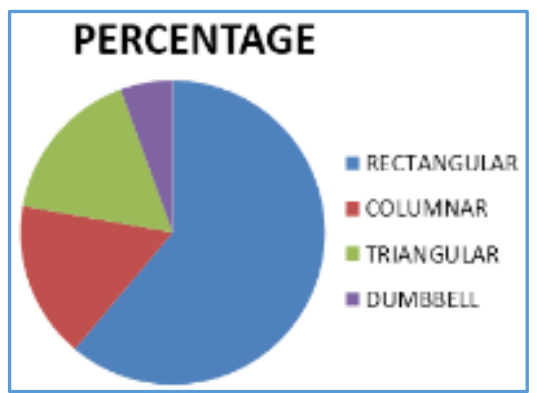

Chart I. Shape of Caudate Lobe

Caudate lobes of our study showed mainly rectangular shape (Fig. I) (61.11\%), columnar (Fig. IV) or elongated caudate lobes and triangular caudate lobes (Fig. III) in equal proportion (16.67\%) and dumbbell-shaped lobes (Fig. II) were $5.55 \%$ (Table I and Chart I).

Papillary processes, caudate processes and notches were seen in most of the livers (77.78\%). They were absent in rest of the livers studied (22.22\%).

\begin{tabular}{|c|c|c|c|}
\hline Parameters & Range (cm) & $\begin{array}{c}\text { Mean } \\
\text { (cm) }\end{array}$ & $\begin{array}{c}\text { Standard } \\
\text { Deviation }\end{array}$ \\
\hline Vertical length of C L & $3.2-8 \mathrm{~cm}$ & 5.4 & 6.70 \\
\hline $\begin{array}{c}\text { Max transverse } \\
\text { diameter of CL }\end{array}$ & $1.5-4.5 \mathrm{~cm}$ & 2.58 & 0.71 \\
\hline $\begin{array}{c}\text { Vertical length of } \\
\text { right lobe }\end{array}$ & $8-16 \mathrm{~cm}$ & 11.31 & 1.96 \\
\hline $\begin{array}{c}\text { Transverse diameter } \\
\text { of right lobe }\end{array}$ & $4.8-10 \mathrm{~cm}$ & 7.39 & 1.19 \\
\hline Area of C L & $5.25-32 \mathrm{~cm}^{2}$ & $13.61 \mathrm{~cm}^{2}$ & 5.7 \\
\hline Area of right lobe & $39.36-144 \mathrm{~cm}^{2}$ & $84.60 \mathrm{~cm}^{2}$ & 26.14 \\
\hline $\begin{array}{c}\text { Ratio of C L to right } \\
\text { lobe }\end{array}$ & $0.06-0.41$ & 0.17 & 0.08 \\
\hline \multicolumn{2}{|c|}{ Table II. Measurements of Liver } \\
\hline
\end{tabular}

Table II shows various measurements of the livers among the study group. A mean length of $5.4 \mathrm{~cm}$ and breadth of 2.58 $\mathrm{cm}$ were noted for the caudate lobes and mean length of $11.31 \mathrm{~cm}$ and breadth of $7.39 \mathrm{~cm}$ for right lobes respectively.

Ratio of caudate lobe to right lobe area ranged from 0.06 to 0.41 with a mean of 0.17 . Cirrhotic livers may show ratio over 0.65 .

\begin{tabular}{|c|c|c|c|c|}
\hline Vessel & $\begin{array}{c}\text { Number of } \\
\text { livers with } \\
\text { branches } \\
\text { from left } \\
\text { side alone } \\
\text { to Caudate } \\
\text { lobe }\end{array}$ & $\begin{array}{c}\text { Number of } \\
\text { branches } \\
\text { from left } \\
\text { side and } \\
\text { from } \\
\text { junction of } \\
\text { left and } \\
\text { right side } \\
\text { to Caudate } \\
\text { lobe }\end{array}$ & $\begin{array}{c}\text { Number of } \\
\text { livers with } \\
\text { branches } \\
\text { from both } \\
\text { left and } \\
\text { right sides } \\
\text { to Caudate } \\
\text { lobe }\end{array}$ & $\begin{array}{c}\text { Number of } \\
\text { livers with } \\
\text { branches } \\
\text { from } \\
\text { junction of } \\
\text { left and } \\
\text { right sides } \\
\text { to Caudate } \\
\text { lobe }\end{array}$ \\
\hline $\begin{array}{c}\text { Hepatic } \\
\text { artery }\end{array}$ & 29 & 5 & 5 & 6 \\
\hline Bile duct & 31 & 1 & 1 & 2 \\
\hline \multicolumn{7}{|c|}{ Table III. Branching Pattern of Vessels and Ducts to } \\
\hline \multicolumn{5}{|c|}{ Caudate Lobe } \\
\hline
\end{tabular}

Table III shows livers with their branches of blood vessels and ducts to segment I.

Portal vein was seen to supply majority of caudate lobes through a single branch, usually from the left branch in $55.55 \%$ livers. $13.89 \%$ of caudate lobes had branches from left branch and also from junction of left and right branches. Another $13.89 \%$ livers had branches from both right and left branches supplying their caudate lobes. 6 of the caudate lobes were supplied by a single branch from the junction alone $(16.67 \%)$. None of the caudate lobes in the study was supplied by the right branch of portal vein alone (chart II). One liver had 2 branches from left branch of portal vein itself.

Majority of caudate lobes had a single branch of hepatic artery from left branch supplying them $(80.56 \%)$ and only 3 livers $(8.33 \%)$ had supply from right branch alone. Another $8.33 \%$ had 2 branches to their caudate lobes (chart III).

Biliary drainage was mostly noted to be through a single duct from left side in our study (86.11\%) as shown in chart IV.

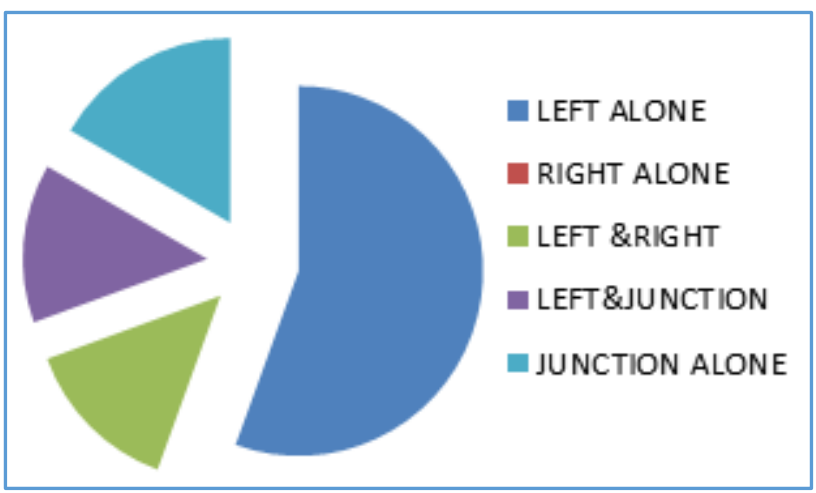

Chart II. Portal Vein Branching Pattern to Caudate Lobe 


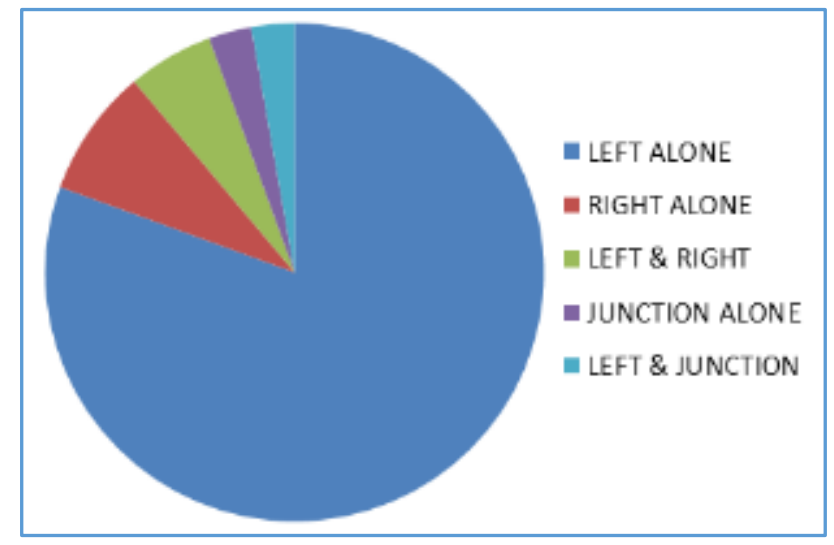

Chart III. Hepatic Artery Branching Pattern to Caudate Lobe

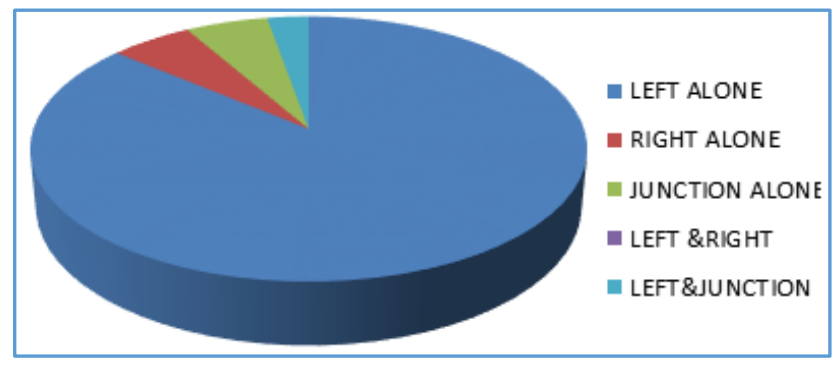

Chart IV. Bile Duct Draining Caudate Lobe

\section{DISCUSSION}

The liver is anatomically divided into left, right, caudate and quadrate lobes based on its peritoneal attachments. ${ }^{1}$ The caudate lobe is a distinct lobe, located on the posterior surface of liver between the groove for inferior vena cava to the right, fissure for ligamentum venosum to the left, and porta hepatis anteriorly. ${ }^{2}$

Gross abnormalities of the liver are rare in spite of its complex development. More common abnormalities are the abnormalities in form and less common ones are the presence of accessory lobes or livers. ${ }^{3}$ Acquired changes in liver morphology are represented by the following characteristic features,(1) linguiform lobes,(2) costal organ with very small left lobe,(3) deep renal impressions and "corset" type constrictions and local inflammation of the organ or gall bladder. ${ }^{4}$ Accessory lobes arise most commonly from right lobe and may project in any direction. Among them, Riedel's lobe is the most common which descends inferiorly along the right lateral margin. ${ }^{5}$ Most of the accessory lobes and hypertrophic caudate lobe extensions and accessory fissures may disappear during postnatal changes in the liver.

Accessory hepatic fissures are potential sources of diagnostic errors on both sonography and CT. Radiological and corrosion cast studies have attributed the formation of sulci to existence of weak zone of hepatic parenchyma, represented by portal fissures between adjacent sagittal portal territories. These weak zones offer a lower resistance to external pressure of diaphragm. ${ }^{6}$

According to Mamatha et al, notching along inferior border of caudate lobe was seen in $18 \%$ of livers studied and vertical fissures in $30 \%$, prominent papillary process in $32 \%$. Accessory fissures and grooves were more seen in right lobe. $60 \%$ of their study showed normal appearance. One caudate lobe in our study showed an accessory fissure (Fig.VI) extending from the superior surface downwards, and Papillary and caudate processes along with notches between them were seen in $77.78 \%$ of livers. An accessory lobe (Fig.V) was also noted. Chavan ${ }^{7}$ et al observed absence of papillary process in all their study group, whereas Sahni ${ }^{8}$ et al reported papillary process in $33 \%$. Kogure et $\mathrm{al}^{9}$ noticed notches in $50 \%$ of caudate lobes in patients undergoing hepatectomy. Singh 10 et al observed a notch on the superior border of caudate lobe. Normal anatomy of caudate lobe can create several pitfalls that may lead mistakenly to a diagnosis of disease. Auh et al ${ }^{11}$ found that on CT, a normal or small papillary process may be mistaken for enlarged porta hepatis lymph nodes. Enlarged papillary process can displace gastric antrum and duodenum anteriorly mimicking right-sided retroperitoneal mass. However, Atkan et al noticed absence of caudate lobe in $7.14 \%$ of their study ${ }^{12}$ which was in accordance to Mamatha et al.

Caudate lobe enlargement accompanies occlusion of hepatic veins. Venous drainage of caudate lobe is by emissary veins which pass directly from caudate lobe to inferior vena cava. ${ }^{13}$

Shape of caudate lobe was seen to be triangular, square, inverted flask shaped, oval and pear shaped by Chavan et al. One case of dumbbell-shaped caudate lobe was seen by Mamatha et al, as in Nayak's ${ }^{14}$ study. Joshi et al ${ }^{15}$ reported $58 \%$ rectangular, $20 \%$ bicornuate, and pear shaped, quadrate, oblong, heart shaped, square, and inverted pearshaped Caudate lobes in $22 \%$ of their study, whereas we found four different shapes of caudate lobes; which were rectangular (61.11\%), columnar/elongated (16.67\%), triangular (16.67\%) and dumbbell shaped (5.55\%). Accessory caudate lobe or caudate lobe duplication may be present.

Vakili et $\mathrm{al}^{16}$ noticed that caudate process duct drains into right hepatic duct (85\%) and left part of caudate lobe into left hepatic duct (93\%). Our study revealed that biliary drainage of caudate lobe was by branch of left hepatic duct alone (Fig. IX) in $86.11 \%$ and by right alone in only $5.55 \%$. A branch from junction of left and right hepatic ducts drained 5.55\% caudate lobes and two branches, one from left and another from junction of left, and right hepatic ducts drained another $5.55 \%$ caudate lobes. Blumgart et al ${ }^{17}$ states that biliary drainage of caudate lobe is only into LHD in 15\% of his study and only into RHD in 5\% cases.

Proper oxygenation \& functioning of liver cells is dependent on portal venous flow. Number of branches of ducts also varies.

Caudate lobe is part of right lobe but functionally part of left lobe as it receives blood supply from left branch of hepatic artery and portal vein and delivers bile to left hepatic duct. ${ }^{18}$ Caudate Lobe undergoes compensatory hypertrophy while rest of the liver shrinks as reported by many studies. ${ }^{19}$, 20, 21 The caudate and papillary processes share blood supply and drainage hypothesised to underlie compensatory hypertrophy of caudate lobe in cirrhosis. ${ }^{22}$.

According to Kogure et al, the caudate branches ramified from left portal vein in $48.6 \%$ and from right portal vein in $22.9 \%$ and from bifurcation in $17 \%$ and from main portal trunk in $11.5 \%$ of livers studied. According to them, most common origin of portal branch to caudate lobe was from left portal vein as was noted in our study (Fig. VII) (55.55\%). None of the caudate lobes studied by us showed caudate 
branches from right branch of portal vein alone. 13.89\% caudate lobes had branches from right side or from junction of left and right branch in addition to a branch from left branch of portal vein (Fig. VIII).

Proper hepatic artery passes anterior to portal vein as it ascends to the epiploic foramen and at porta hepatis branches to right and left. Right hepatic artery usually crosses posterior to common hepatic duct. Its anterior division supplies segment I. 80.56\% caudate lobes had branches from left hepatic artery alone supplying them and only $8.33 \%$ were supplied by branch from right hepatic artery alone. Pons hepaticus is bridging of inferior vena cava. It is said to be complete when it covers posterior aspect of retrohepatic segment of inferior vena cava. ${ }^{23}$ No pons hepaticus was encountered in our study.

Caudate lobe length varied from 3.2 to $8 \mathrm{~cm}$ with mean of $5.5 \mathrm{~cm}$ and SD of 6.7. Transverse diameter of caudate lobe had a mean breadth of $2.58 \mathrm{~cm}$ with SD of 0.71 which is similar to study of Arora et al. ${ }^{24}$

Range of right lobe length was $8-16 \mathrm{~cm}$ with mean of 11.31 and SD 1.96 and mean breadth of right lobe was 7.39 $\mathrm{cm}$.

The range of surface area of caudate lobe ranged from 5.25 to 32 sq. $\mathrm{cm}$ with a mean of 13.61 sq. $\mathrm{cm}$ and of right lobe varied from 39.36 to $144 \mathrm{sq}$. cm with a mean of $84.60 \mathrm{sq}$ $\mathrm{cm}$. The ratio of the two ranged between 0.061 to 0.410 with a mean of 0.17 and S D of 0.078 in our study, whereas the range is $0.07-0.29$ and mean of 0.16 and Caudate lobe to right lobe ratio more than 0.65 is seen in conditions like cirrhosis as reported by Arora et al.

\section{CONCLUSION}

Shape of caudate lobe is variable as is the presence of papillary processes, caudate processes and notches. Even though caudate lobe is part of right lobe anatomically, it is functionally a part of left lobe as it receives blood supply from left branches of portal vein and hepatic artery and is drained by left hepatic ducts, and is confirmed by our study.

\section{REFERENCES}

[1] Standring S, Borley NR. Gray's Anatomy: the anatomical basis of clinical practice. $40^{\text {th }}$ edn. London: Elsevier 2008:1163-72.

[2] Xu LN, Zhi-Qiang Huang. Resection of hepatic caudate lobe hemangioma: experience with 11 patients. Hepatobiliary Pancreat Dis Int 2010;9(5):487-91.

[3] Fraser CG. Accessory lobes of the liver. Annals of Surgery 1952;135(1):127-9.

[4] Mamatha Y, Murthy CK, Prakash BS. Study on morphological surface variations in human liver. Ini J Health Sci Res 2014;4(11):97-102.

[5] Royer MF. Vias Biliares e pancreas. Rio de Janero, Brazil: Guanabara Koogan 1959.

[6] Macchi V, Feltrin G, Parenti A, et al. Diaphragmatic sulci and portal fissures. Journal of Anatomy 2003;202(3):303-8.
[7] Chavan NN, Wabale RN. Morphological study of caudate lobe of liver. Indian Journal of Basic and Applied Med Res 2014;3(3):204-11.

[8] Sahni D, Jit I, Sodhi L. Gross anatomy of caudate lobe of the liver. J Anat Soc India 2000;49(2):123-6.

[9] Kogure K, Kuwano H, Fujimaki N, et al. Relation among portal segmentation, proper hepatic vein \& external notch of the caudate lobe in human liver. Ann Surg 2000;231(2):223-8.

[10] Singh R, Singh K, Man S. Duplicate caudate lobe of liver with oblique fissure and hypoplastic left lobe of liver. J Morphol Sci 2013;30(4):309-11.

[11] Auh YH, Rosen A, Rubenstein WA, et al. C T of the papillary process of the caudate lobe of the liver. American Journal of Roentgenology 1984;142(3):5358.

[12] Atkan ZA, Savas R, Pinar Y, et al. Lobe and segment anomalies of the liver. Journal of Anatomical Society of India 2001;50(1):15-16.

[13] Dodds WJ, Erickson SJ, Taylor AJ, et al. Caudate lobe of the liver: embryology and pathology. American Journal of Roentgenol 1989;154:87-93.

[14] Nayak BS. A study on the anomalies of liver in the South Indian cadavers. Int J Morphol 2013;31(2):65861.

[15] Joshi SD, Joshi SS, Athavale SA. Some interesting observations on the surface features of the liver and their clinical implications. Singapore Med J 2009;50(7):715-19.

[16] Vakili K, Pomfret EA. Biliary anatomy and embryology. Surg Clin North Am 2008;88(6):1159-74.

[17] Blumgart LH, Belghiti J. Surgery of the liver, biliary tract and pancreas. 3rd edn. Philadelphia: Elsevier 2007:3-30.

[18] McMinn RMH. Vast's Anatomy-regional and applied. $8^{\text {th }}$ edn. Churchill Livingstone 1990: p. 346.

[19] Berry M, Suri. G I T Radiology- liver and biliary tract. Jaypee Brothers Medical Publication 2000:268-71.

[20] Giorgio A, Amoroso P, Lettieri G, et al. Value of caudate to right lobe ratio in diagnosis with US. Radiology 1986;161(2):443-5.

[21] Awaya H, Mitchell DG, Kamishima T, et al. Cirrhosis: modified caudate-right lobe ratio. Radiology 2002;224(3):769-74.

[22] Ortale JR, Borges Keiralla LC. Anatomy of the portal branches and the hepatic veins in the caudate lobe of the liver. Surg Radiol Anat 2004;26(5):384-91.

[23] Sagoo MG, Aland RC, Gosden E. Morphology and morphometry of the caudate lobe of the liver in two populations. Anat Sci Int 2016.

[24] Arora NK, Srivastava S, Haque M, et al. Morphometric study of caudate lobe of liver. Ann Int Med Den Res 2016;2(1):275-9. 